\title{
Effectiveness of two-dimensional CFD simulations for Darrieus VAWTs: a combined numerical and experimental assessment
}

\author{
Alessandro Bianchini ${ }^{1}$, Francesco Balduzzi ${ }^{1}$, Peter Bachant ${ }^{2}$, Giovanni Ferrara ${ }^{1}$, Lorenzo \\ Ferrari $^{3 *}$
}

\footnotetext{
${ }^{1}$ Department of Industrial Engineering, University of Florence - Via di Santa Marta 3, 50139, Firenze, Italy Tel.+390552758773 - Fax +390552758755 - bianchini@vega.de.unifi.it

${ }^{2}$ Center for Ocean Renewable Energy, University of New Hampshire - Chase Ocean Engineering Laboratory, Durham, N.H.03824 - pxl3@wildcats.unh.edu

${ }^{3}$ Department of Energy, Systems, Territory and Construction Engineering, University of Pisa - Largo Lucio Lazzarino 1, 56122, Pisa, Italy - Tel. +390502217132 - Fax+390502217333 - lorenzo.ferrari@unipi.it

$*$ contact author
}

\begin{abstract}
Thanks to the continuous improvement of calculation resources, computational fluid dynamics (CFD) is expected to provide in the next few years a cost-effective and accurate tool to improve the understanding of the unsteady aerodynamics of Darrieus wind turbines. This rotor type is in fact increasingly welcome by the wind energy community, especially in case of small size applications and/or non-conventional installation sites.

In the present study, unique tow tank experimental data on the performance curve and the near-wake structure of a Darrieus rotor were used as a benchmark to validate the effectiveness of different CFD approaches. In particular, a dedicated analysis is provided to assess the suitability, the effectiveness and the future prospects of simplified two-dimensional (2D) simulations. The correct definition of the computational domain, the selection of the turbulence models and the correction of simulated data for the parasitic torque components are discussed in this study. Results clearly show that, (only) if properly set, two-dimensional CFD simulations are able to provide - with a reasonable computational cost - an accurate estimation of the turbine performance and also quite reliably describe the attended flow-field around the rotor and its wake.
\end{abstract}

\section{Keywords}

Darrieus, wind turbine, unsteady Navier-Stokes simulations, CFD, transitional turbulence model, experiments

\section{Nomenclature}

$\underline{\text { Latin symbols }}$

A turbine frontal area

ADV

Acoustic Doppler Velocimeter

$\left[\mathrm{m}^{2}\right]$ 


\begin{tabular}{|c|c|c|c|}
\hline 41 & $c$ & blade chord & {$[\mathrm{m}]$} \\
\hline 42 & $c_{P}$ & power coefficient & {$[-]$} \\
\hline 43 & $C_{A}$ & equivalent chord of the struts & {$[\mathrm{m}]$} \\
\hline 44 & BEM & Blade Element Momentum & \\
\hline 45 & CFD & Computational Fluid Dynamics & \\
\hline 46 & $D$ & turbine diameter & {$[\mathrm{m}]$} \\
\hline 47 & $H$ & turbine height & {$[\mathrm{m}]$} \\
\hline 48 & $k$ & turbulent kinetic energy & {$\left[\mathrm{m}^{2} / \mathrm{s}^{2}\right]$} \\
\hline 49 & LLT & Lifting Line Theory & \\
\hline 50 & $O$ & centroid of the generic element on the strut & \\
\hline 51 & RANS & Reynolds Averaged Navier-Stokes & \\
\hline 52 & $R$ & turbine radius & {$[\mathrm{m}]$} \\
\hline 53 & $\operatorname{Re}$ & Reynolds Number & {$[-]$} \\
\hline 54 & $\operatorname{Re}_{\theta}$ & Momentum Thickness Reynolds Number & {$[-]$} \\
\hline 55 & $S$ & tunnel cross section area & {$\left[\mathrm{m}^{2}\right]$} \\
\hline 56 & SST & Shear Stress Transport & \\
\hline 57 & $T$ & torque per unit length & {$[\mathrm{Nm} / \mathrm{m}]$} \\
\hline 58 & $T S R$ & tip-speed ratio & \\
\hline 59 & $U$ & wind speed & {$[\mathrm{m} / \mathrm{s}]$} \\
\hline 60 & $U^{\prime}$ & local absolute wind speed on the rotor & {$[\mathrm{m} / \mathrm{s}]$} \\
\hline 61 & VAWTs & Vertical-Axis Wind Turbines & \\
\hline 62 & $W$ & relative speed & {$[\mathrm{m} / \mathrm{s}]$} \\
\hline 63 & $y^{+}$ & dimensionless wall distance & {$[-]$} \\
\hline \multicolumn{4}{|l|}{64} \\
\hline 65 & Greek symbols & & \\
\hline 66 & $\gamma$ & intermittency & \\
\hline 67 & $\vartheta$ & azimuthal angle & [deg] \\
\hline 68 & $v$ & kinematic viscosity & {$\left[\mathrm{m}^{2} / \mathrm{s}\right]$} \\
\hline 69 & $\rho$ & density & {$\left[\mathrm{kg} / \mathrm{m}^{3}\right]$} \\
\hline 70 & $\sigma$ & standard deviation of experimental wake data & {$[-]$} \\
\hline 71 & $\omega$ & specific turbulence dissipation rate & {$[1 / \mathrm{s}]$} \\
\hline 72 & $\Omega$ & revolution speed & {$[\mathrm{rad} / \mathrm{s}]$} \\
\hline \multicolumn{4}{|c|}{73} \\
\hline 74 & Subscripts & & \\
\hline 75 & $\overline{0}$ & value at inlet/infinity & \\
\hline 76 & ave & averaged value & \\
\hline 77 & $\mathrm{j}$ & generic element & \\
\hline 78 & res & resistant & \\
\hline 79 & $\mathrm{x}$ & streamwise direction & \\
\hline 80 & & & \\
\hline
\end{tabular}

\section{Introduction}

\subsection{Background}

After most pilot research projects on vertical-axis wind turbines (VAWTs) came to a standstill in the mid 90's [1], these turbines are presently being re-discovered by researchers and manufacturers. Among the different turbine architectures, the Savonius rotor is indeed especially welcome in case of small installations, where an effective self-starting is required [2], in hydrokinetic applications [3] or in hybrid applications as add-on to lift-based devices 88 to improve the self-starting [4]. On the other hand, the Darrieus turbines are suggested as a 
valuable alternative to horizontal-axis wind turbines (HAWTs) for power production is small and medium-size applications [5] or even in very large ones [6]. Some inherent advantages of the Darrieus concept (performance independence on wind direction, generator positioned on the ground [1], low noise emissions [7], enhanced performance in skewed flows [8], thanks to increased virtual swept area) may indeed outweigh their disadvantages in specific applications. In particular, increasing attention is being devoted to applications in the urban environment [9], where the attended flow conditions include high turbulence levels and misaligned flows, or in floating platforms [10], where the independence on wind direction and the mass concentration at the ground allow a more effective control of the system oscillations. Moreover, VAWTs are often preferred to other turbine types in densely populated areas because they are perceived as aesthetically more pleasant, thus easier to integrate in the landscape [11]. In particular, different architectures are available for this type of rotors [12] in terms of blades' number, blades' shape (straight, helix, bended, etc.) or struts' types.

In order to make this technology competitive from an industrial point of view, however, an improvement in the design is needed, particularly focusing on extending the energy harvesting at low wind speeds, as recently shown by [13].

The aerodynamic design of these rotors, especially in the "first design phase", has been historically carried out with low-order methods, like the Blade Element Momentum (BEM) theory [14-15] or lifting line theory (LLT) methods [16-17]. More recently, however, the intrinsic limitations of these models, in which the airfoils are modeled with lumped parameters (lift, drag and moment coefficients), made clear to researchers that more powerful tools are needed in order to understand in detail some of the complicated physical phenomena taking place during the revolution of Darrieus rotors. This conclusion was recently drawn in [18], where the authors carried out a critical survey on the accuracy of the aforementioned methods using different test cases. In particular, some of the phenomena that cannot be reduced to a lumped-parameter analysis are the interaction of the blades with macro vortices [19], the flow curvature effects [20-21] (i.e. the effects of virtual airfoil cambering and the extra-incidence induced by the rotation of an airfoil inside a linear flow field) or the dynamic stall [22] induced by the continuous and fast variation of the incidence angle.

If experimental testing is often extremely expensive, Computational Fluid Dynamics (CFD) can provide versatile and accurate means to improve the understanding of Darrieus VAWT unsteady aerodynamics and achieve higher-performance in Darrius turbine design. The use of unsteady Reynolds Averaged Navier-Stokes (RANS) CFD for simulating timedependent Darrieus turbine aerodynamics is then rapidly increasing due to both the ongoing development and deployment of more powerful high-performance computing hardware (e.g. large clusters of multi- and many-core processors [23]) and also the development of computationally more efficient algorithms or dedicated codes [24].

\subsection{Literature CFD studies on Darrieus VAWTS}

Early assessments of the unsteady RANS CFD technology for Darrieus rotor aerodynamics, aiming primarily at thoroughly investigating the complex fluid mechanics of these machines, made use mainly of a two-dimensional approach (e.g. [25-26]). An extensive literature review on these studies has been recently provided by [27], where the authors presented and explained the most common settings and models used for the simulation of these turbines. Moreover, the authors also proposed a "best simulation" strategy in terms of CFD models, meshing and time-stepping choices, simulation settings.

The use of a 2D approach was motivated by the need of containing the computational cost of the simulations themselves, since the fully-unsteady solution of the flow field past rotating Darrieus blades has some strict requirements in terms of both spatial and temporal 
discretizations. For example, ref. [28] showed that this type of simulation is particularly sensitive to the spatial discretization; in [29], specific criteria based on dimensionless numbers confirmed this assumption and highlighted the need of a remarkable grid refinement in a 1-chord-diameter area around the airfoil. Moreover, according to [29], the Courant number has to be contained to very low values in order to properly capture the transient flow field evolution. If these requirements are fulfilled, recent works (e.g. [30]) showed a promising agreement between 2D simulations and experiments. Notwithstanding this, however, some very interesting phenomena are intrinsically discarded by two-dimensional analyses (e.g. tip effects, vortices propagation in the span direction, etc.).

On the other hand, since the very first studies on CFD analyses for Darrieus rotors, researchers have always longed to perform three dimensional tests of these machines in order to fully understand some phenomena that are usually only hypothesized or modeled empirically. In the last few years, thanks to the increase of computational resources, 3D CFD analyses have then received increasing attention and a great number of studies have been published, analysing for example new turbine architectures [32-33], different shapes of the supporting arms [34] or the effect of a misaligned flow [35]. In particular, it was shown in [36] that a 3D approach can definitely improve the accuracy of the simulations and provide a detailed description of the entire flow-field around a H-Darrieus rotor. On the other hand, these simulations become extremely expensive from a computational point of view, especially in case proper spatial and temporal refinement have to be guaranteed, as discussed in [37], where a high-computing cluster was used for a very accurate simulation of a single blade in Darrieus motion. In [36], for example, an increase of the computational cost of about four orders of magnitude between 2D and 3D simulations was noticed. In any case, 3D simulations are presently not affordable for industrial purposes. In this view, the assessment of a 2D strategy able to give sufficiently reliable aerodynamic results is thought of interest, since it would provide an effective tool to achieve a better understanding of some main physical phenomena and thus to ensure a better design of future machines.

\subsection{Aim of the present study}

In the present study, unique experimental data on the performance curve and the nearwake structure of a Darrieus rotor tested in a large tow tank were used as a benchmark to validate the effectiveness of a two-dimensional CFD approach in comparison to a fully threedimensional one. In particular, the correct definition of the computational domain, the selection of the turbulence model and the correction of simulated data for the parasitic torque components are discussed in this work.

The paper is organized as follows: Section 2 summarizes the main features of the case study, the experimental layout and available measurements. Section 3 is dedicated to the description of the numerical approaches, including the analysis of grid characteristics and simulation settings. Results and comparisons with respect to both three-dimensional simulations and experiments are reported in section 4, while a summary of the study and concluding remarks are finally provided in section 5.

\section{Case study and experiments}

\subsection{Study turbine}

The turbine modeled in this study (Fig. 1) was the Reference Vertical Axis Turbine (UNH-RVAT) of the University of New Hampshire, developed by the Center for Ocean Renewable Energy (UNH-CORE), in the spirit of, but not geometrically identical to, the DOE 
Reference Model turbine designed by Sandia National Laboratory in 2011 [38], often referred to as "RVAT" (Reference Vertical Axis Turbine) or "RM2" (Reference Model 2).

The model is made of a high solidity (blade chord-to-radius ratio equal to 0.28 ) rotor constructed from $0.14 \mathrm{~m}$ chord length NACA 0020 foils with $1 \mathrm{~m}$ span, mounted at $1 \mathrm{~m}$ diameter. The blades are supported by three struts attached at mid-chord and mid-span. The struts are also shaped as NACA 0020 airfoils, in order to contain their parasitic torque during the revolution. The central tower was made of an aluminium splined shaft having a mean dimeter of $0.095 \mathrm{~m}$. For additional details on the model please refer to [36,39].

The UNH-RVAT was the study case of various experimental and numerical investigations $[36,39,40]$, which demonstrated unique near-wake mean velocity field of the rotor, its relevance to wake recovery, and its Reynolds number dependence. In further detail, the open performance and near-wake dataset [41] for the UNH-RVAT was used for validation in the present study.

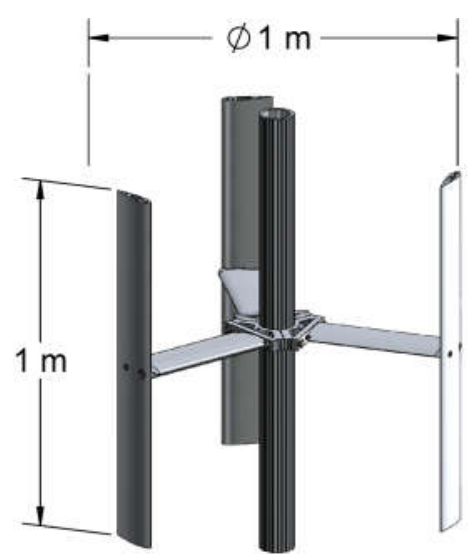

Fig. 1 - Study turbine [39].

\subsection{Experiments}

The experimental validation dataset [10] employed here was acquired in the $36 \mathrm{~m}$ long UNH-CORE tow tank. Tests were carried out using a water speed of $1 \mathrm{~m} / \mathrm{s}$, giving a reference value of the turbine diameter Reynolds number of approximately $1 \cdot 10^{6}$. More specifically, at the lowest regime (TSR=1.1) the chord-based Reynolds number (calculated with an estimation of the relative speed based on a BEM approach) was approximately in the range between $3.0 \cdot 10^{4}$ and $3.5 \cdot 10^{5}$, while at the highest one $(\mathrm{TSR}=3.2)$ it was in the range between $4.0 \cdot 10^{5}$ and $6.8 \cdot 10^{5}$.

The tow tank, whose cross section is sketched in Fig.2, is $2.44 \mathrm{~m}$ deep and $3.66 \mathrm{~m}$ wide. Based on the present turbine frontal area, the tank cross section produced a blockage ratio of approximately $11 \%$.

The experimental setup, including the supporting frame and the instrumentation is also depicted in Fig. 2. Carriage motion was actuated by a permanent magnet servomotor and timing belt, providing highly accurate tow velocities, independently verified by a highresolution linear encoder. The turbine was installed in the tow tank by means of a dedicated supporting frame, which was built from NACA 0020 struts, mounted to the carriage via linear bearings. The turbine shaft was loaded by a servo motor and gearhead, which provided precise control of mean turbine TSR. 


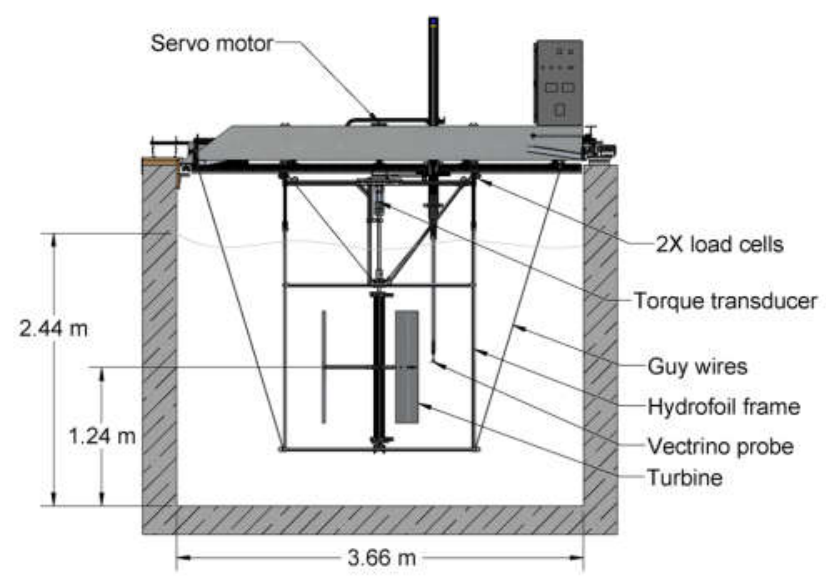

Fig. 2 - Drawing of the turbine test bed installed in the UNH tow tank [39].

Power and overall rotor drag coefficients were measured over a range of TSRs, and the upper half of the wake at TSR=1.9 and one rotor diameter downstream was measured using a Nortek Vectrino+ acoustic Doppler velocimeter (ADV), which has an approximately $6 \mathrm{~mm}$ diameter sampling volume and sampled at $200 \mathrm{~Hz}$. The ADV and data acquisition systems' sampling times were synchronized by triggering the start of data acquisition via a pulse sent from the motion controller. Additional details of the turbine and experimental setup are described in [39].

\section{Numerical techniques}

In this study, different numerical techniques have been considered. In particular, the results of a previous full-3D approach [36] were first considered as a benchmark for other simulations, being the ones thought to provide the most reliable description of the turbine behavior (Section 3.1).

Focus was then given (Section 3.2) to 2D simulations using the commercial solver ANSYS $^{\circledR}$ FLUENT $^{\circledR}$ and the comprehensive approach developed in the last few years by some of the authors $[27,29]$. In this second type of simulations, dedicated sensitivity analyses on the proper definition of the computational domain (Section 3.3) and on the turbulence model selection (Section 3.4) were also provided.

\subsection{Former results of OpenFOAM simulations}

The open-source CFD package OpenFOAM has been used recently by one of the authors to model the UNH-RVAT in two and three dimensions using the $\kappa$ - $\omega$ SST and the Spalart-Allmaras turbulence models [40]. The 2D models both dramatically over predicted performance, whereas the 3D simulations predicted performance more closely matching experiment, with the Spalart-Allmaras model performing best. As will be extensively discussed later on in the study, it should be noted that, in the 2D case simulations, the tow tank width was matched, and therefore blockage was artificially increased, which could explain the exaggerated performance, as more flow was forced through the turbine.

\subsection{D simulations with ANSYS ${ }^{\circledR}$ FLUENT $^{\circledR}$}

A robust numerical approach using the commercial solver ANSYS ${ }^{\circledR}$ FLUENT ${ }^{\circledR}[41]$ has been developed in the last few years by some of the authors (e.g. [27]). The fluid mean was water at exactly the same temperature measured in the experimental tests $\left(19.5{ }^{\circ} \mathrm{C}\right)$, leading to kinematic viscosity $v=1.0115 \cdot 10^{-6} \mathrm{~m}^{2} / \mathrm{s}$. 
The time-dependent unsteady RANS approach is used in its pressure based formulation, which showed a higher accuracy for these simulations [27]. The Coupled algorithm is preferred to handle the pressure-velocity coupling, since the dedicated sensitivity analyses of [27] showed a superior robustness of this algorithm when different meshes, timesteps, or rotating speeds are used. The second order upwind scheme is applied to the spatial discretization of the whole set of Navier-Stokes and turbulence equations, as well as the bounded second order for the time differentiation to obtain a good resolution. For each operating condition, the global convergence is defined by fixing a periodicity error threshold equal to $0.1 \%$ between the mean values of the torque coefficient over two subsequent revolutions normalized by the mean value over the second period of the pair.

In order to allow the physical revolution of the turbine, the sliding-mesh model of the solver is used. The simulation domain, whose dimensions will be discussed in Section 3.3, is then divided into two subdomains $[27,43]$, i.e. a circular rotating zone containing the turbine and a rectangular fixed outer zone determining the overall domain extent (Fig. 3(a)). Further details can be found in Section 3.3.

An unstructured triangular mesh is applied to discretize the whole domain, except for the boundary layer region where a quadrilateral structured O-grid is used (Fig. (3b)). In previous studies [27,29,44], it was shown that the number of nodes in which the airfoil is discretized is crucial for the determination of both the attack angle of the incoming flow on the blade and the boundary layer evolution from the leading edge to the trailing edge. Moreover, the discretization level adopted in the near-blade region also strongly impacts on the total number of mesh elements, since the growth of the element size has to be accurately controlled [41].
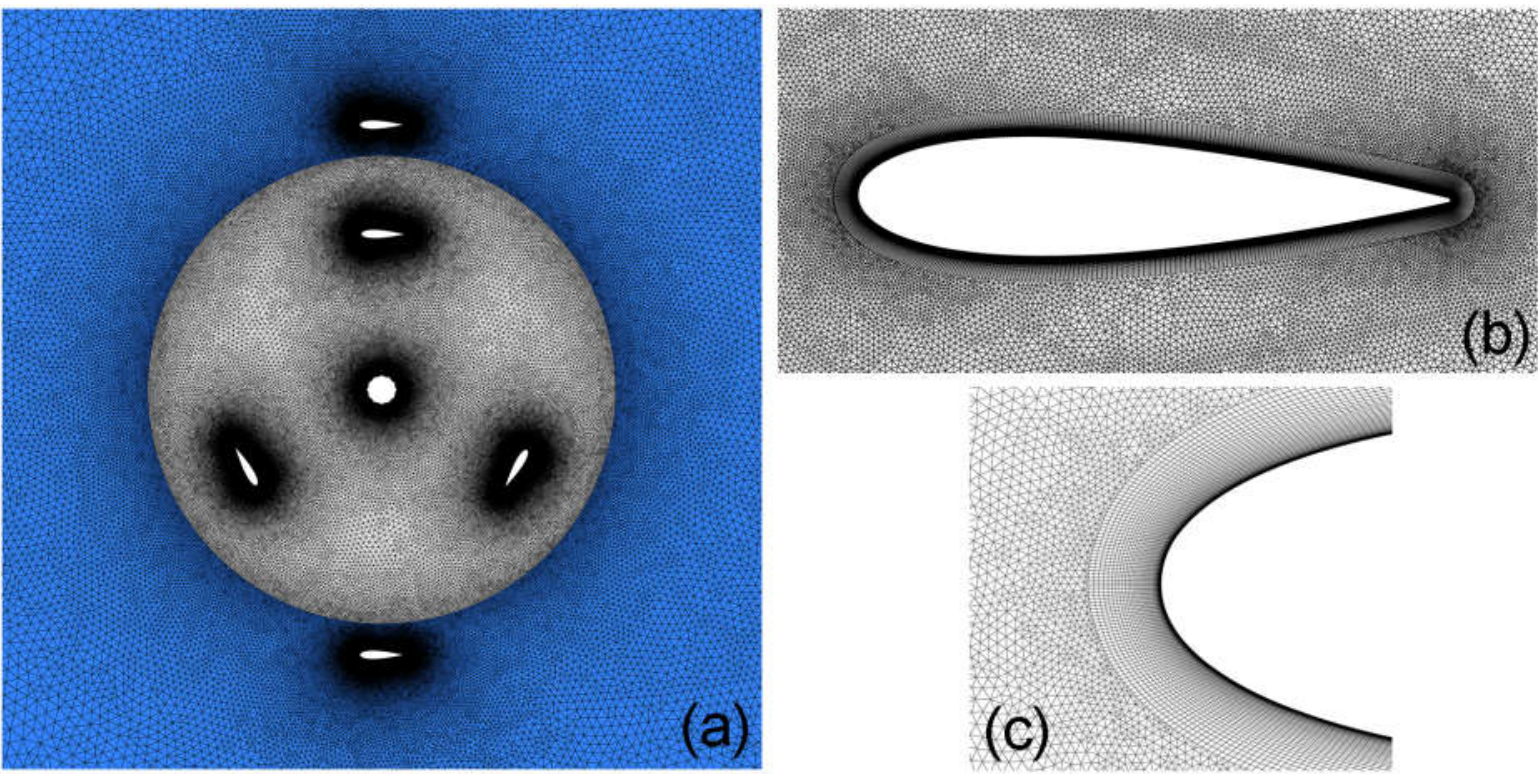

Fig. 3 - Some details of the computational mesh: (a) rotating region and supporting struts; (b) airfoil; (c) leading edge.

For the present study case, initial meshes were created based on previous experience on similar NACA 4-digits VAWTs airfoils [20-21,27,41]; the fulfillment of the thresholds based on the dimensionless numbers presented in [29] was also ensured. A dimensionless wall distance $y^{+}$lower than 1 was guaranteed in all the cells of the domain at any functioning tipspeed ratio. In particular, two different mesh refinements were provided as a function of the TSR for the unstable and the stable halves of the power curve, respectively. This 
recommendation, proposed by [27] based on detailed comparisons with experimental data, is based on the fact that in the unstable part of the power curve the airfoils undergo large variations on the incidence angle which lead to large zones of separated flow around the airfoils. To properly describe these zones, finer meshes are needed [29], which are conversely superfluous at higher TSRs.

In order to ensure the grid-independency of the results, a first mesh sensitivity analysis was performed at two TSRs (i.e. the design one of TSR=1.9 and an unstable one, TSR=1.4) by doubling the number nodes on both the airfoils' surfaces and on a virtual control circle around them having one chord radius [20-21]. No appreciable torque variation, both in terms of mean value (always lower than $0.1 \%$ ) and of torque profiles (coefficient of determination between the curves higher than 99\% [44]), was measured, ensuring the suitability of the present meshes, whose main features are presented in Tab. 1.

Tab. 1 - Mesh sensitivity for the rotating domain.

\begin{tabular}{|c|c|c|c|c|c|}
\hline Mesh & TSR range & $\begin{array}{c}\text { \# elements in } \\
\text { the rotating } \\
\text { domain }\end{array}$ & $\begin{array}{c}\text { \# nodes on } \\
\text { the airfoil }\end{array}$ & $\begin{array}{c}\text { \# quads' rows } \\
\text { in the } \\
\text { boundary layer }\end{array}$ & $\begin{array}{c}\mathbf{1}^{\text {st }} \text { blade } \\
\text { element } \\
\text { height }\end{array}$ \\
\hline Coarse & $1.9-3.1$ & 276806 & 520 & 50 & $1 \times 10^{-5} \mathrm{~m}$ \\
\hline Refined & $1.0-1.4$ & 593880 & 900 & 50 & $1 \times 10^{-5} \mathrm{~m}$ \\
\hline
\end{tabular}

In addition to the mesh sensitivity analysis inside the rotating region, which definitely represents the most critical issue in ensuring a proper spatial discretization, a check on the refinement in the turbine wake was also carried out. In particular, a "drop-shaped" control zone (depicted in Fig. 4, together with other refinement zones around the struts and the central tower) was defined during the meshing strategy of the stationary domain.

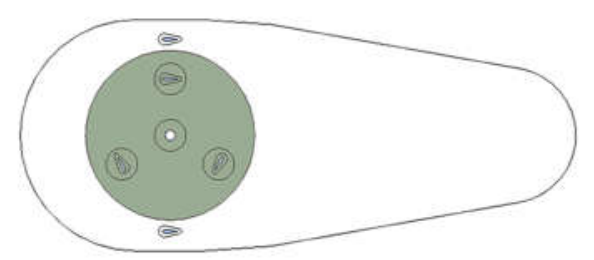

Fig. 4 - Mesh refinement in the wake.

\subsection{Computational domain sensitivity analysis}

In the final version of the stationary mesh (267660 total elements) the elements' size in the contour of the control drop was selected as to guarantee an expansion ratio from the sliding interface of approximately 1.1 .

Starting from this reference dimension, the elements' size was again doubled, obtaining a null variation of the turbine performance, i.e. mean value difference lower than $0.01 \%$ coefficient of determination between the torque profiles higher than $99,9 \%$.

Finally, two different timesteps were also used for the TSRs before or after the curve peak, respectively. According to [27,29], shorter timesteps must indeed be ensured for the functioning points in the unstable part of the curve, where large separations and macrovortices are expected. Following the general criteria of [29], a timestep of $0.14^{\circ}$ was used up to TSR $<1.9$ while a timestep of $0.23^{\circ}$ was considered for higher TSRs. 
As extensively discussed in [27], the dimensions of the computational domain represent a critical issue for the correct setting of two-dimensional CFD simulations of VAWTs. In the present study, three different strategies are analyzed and compared (Fig. 5(a)).
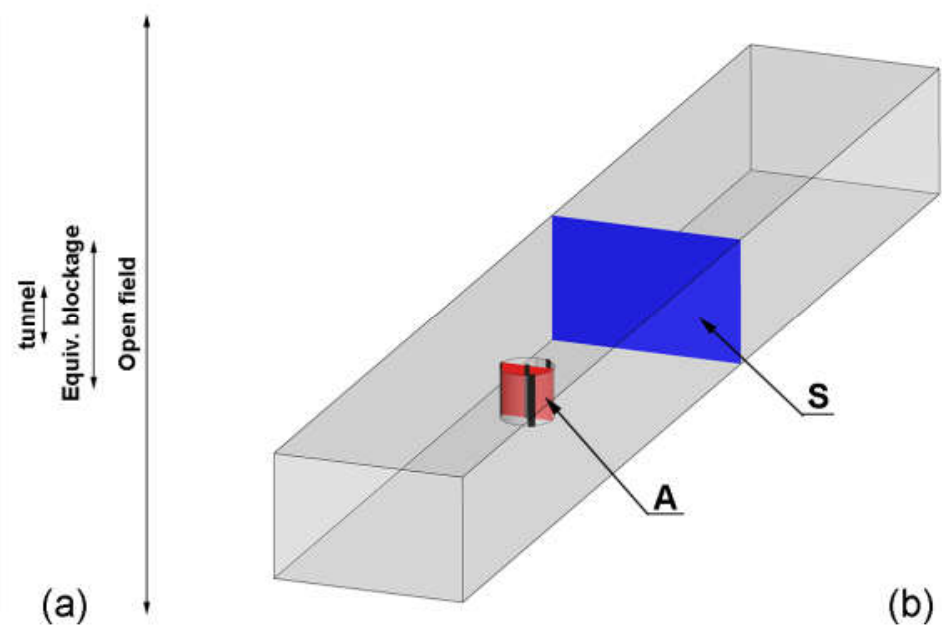

Fig. 5 - Computational domain sensitivity analysis: (a) tested distances of lateral boundaries in the 2D case; (b) blockage equivalence between turbine and tunnel frontal areas.

First, the domain dimensions were defined based on the original proportions of the tow tank in terms of width $(3.7 D)$ and length $(36 D)$. This solution, named "tunnel" in the figure, has been extensively adopted in the literature (e.g. $[19,26,36])$, even if the final results of the correspondent simulations were not always in good agreement with experiments.

Then, a virtual domain width was defined (named "Equivalent Blockage" in the figure) able to reproduce the same ratio available in experiments between the area of the rotor $A$ and the tunnel area $S$ (see Fig. 5(b)). This solution was generated based on the general criteria used to transpose boundary conditions from a three-dimensional domain to a twodimensional one, in which flow passage areas become lines. In this configuration, the width was approximately $9 D$.

Finally, an "Open field" like configuration was considered (36D), in which the domain lateral boundaries were placed far enough to avoid any influence on the rotor, following the sensitivity analysis presented in [27]. This configuration, conventionally used by the authors in recent works [20-21,27,29], ensured a good level of accuracy of numerical results when compared to experiments, even if acquired in a confined wind tunnel. The use of this condition is even more relevant for the present case study since the tow tank is a free surface channel, thus ensuring an even lower actual blockage thanks to the variation of the water level.

\subsection{Turbulence models}

The turbulence closure using the $k-\omega S S T$ model by Menter [45] has been shown in the last few years to be promisingly effective in the CFD study of Darrieus wind turbines, if compared to other models, as discussed in [30]. Some of the authors recently showed that it is able to ensure a better matching with experiments in the correct location of stall on the airfoils during the revolution [27]. Simulations using the approach described in Section 3.2 and the $k-\omega S S T$ turbulence model were also generally able to properly describe both the power curve of the experimental rotors (e.g. see [27,45]). 
As discussed in [20-21], however, whenever the attended blade Reynolds numbers are low enough to make one expect transitional effects (e.g. small rotors at low tip-speed ratios), the use of a transitional turbulence model can be suggested. In particular, the $\gamma-\operatorname{Re}_{\theta}$ transition model (derived from the SST model [47]) was successfully implemented in [20-21], despite its increased computational cost. In addition, good agreement between experimental data and numerical results was obtained in [48] with the transition turbulence model for two different types of H-Darrieus turbines.

On these bases, both turbulence models were used and compared in the present study, showing the additional benefits of the turbulence model especially at the low TSRs of the considered rotor.

\subsection{Resistant torque correction}

As discussed in [40], experiments have been corrected for the parasitic torque coming from the bearings' friction. However, no correction for the aerodynamic resistant torque has been originally provided. In order to make CFD data fully comparable to the experiments, the attended resistant torque was then subtracted to purely aerodynamic data.

The resistant torque was estimated using the lumped parameters model developed by the University of Firenze in [49]. The model makes use of the BEM multitubes approach for the discretization of the rotor; the normal component of the relative velocity on the struts $W \perp$ (i.e. the one really producing drag [50]) is then punctually evaluated at a discrete number of positions $O_{j}$ as a function of the wind velocity reduced by the induction factor of the BEM model $U_{\vartheta}^{\prime}$, the azimuthal angle and the local radius $R_{j}$ for each rotational speed $\Omega$ (see Fig. 6 ). The equivalent drag coefficient of the struts is given as a function of both the struts cross section and the relative Reynolds number. Based on these hypotheses, the average parasitic torque of a rotating strut at a given TSR (i.e. a given $\Omega$ ) is given by Eq. 1, where $C_{A}$ is the equivalent chord of the strut.

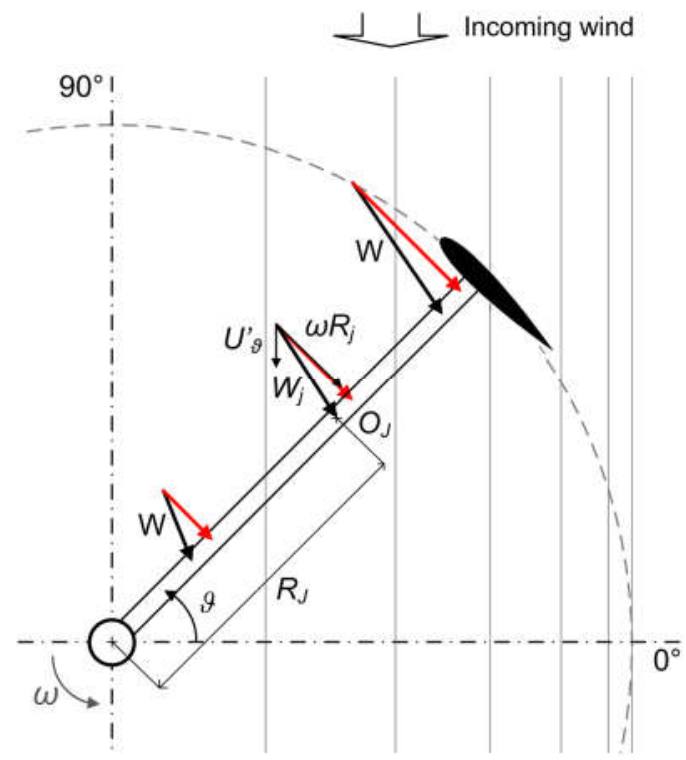

Fig. 6 - Model for the calculation of the struts' resistant torque.

$$
T_{\text {res_ave }}(\Omega)=\frac{1}{4 \pi} \rho C_{A} \int_{0}^{2 \pi} \int_{D_{T} / 2}^{R} C_{D}(\Omega, \vartheta, R) \cdot W_{\perp}(\vartheta, R)^{2} d R d \vartheta
$$


The model has been validated with several experimental campaigns (e.g. [49,51]), obtaining a satisfactory agreement. Based on the model, the resistant torque of the present study turbine as a function of TSR is reported in Fig. 7.

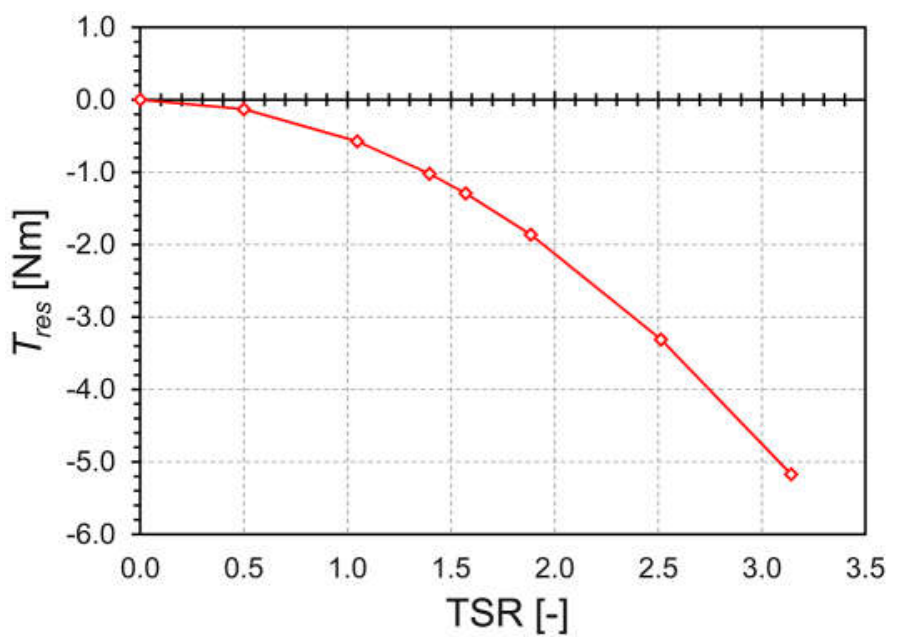

Fig. 7 - Calculated resistant torque for the present study turbine.

\section{Results}

\subsection{Sensitivity analysis on lateral boundaries}

The sensitivity analysis on the domain size was first carried out. Three relevant tipspeed ratios were considered for this analysis, namely $\mathrm{TSR}=1.4, \mathrm{TSR}=1.9$ and $\mathrm{TSR}=2.5$. The first one lies in the unstable part of the operating curve, the second is located near the peak performance, while the third represents a stable functioning condition. Fig. 8 compares the experimental power curve of the rotor with the numerical results using the "tunnel", the "equivalent blockage" and the "open field" configurations described in Section 3.3 (all corrected for the resistant torque).

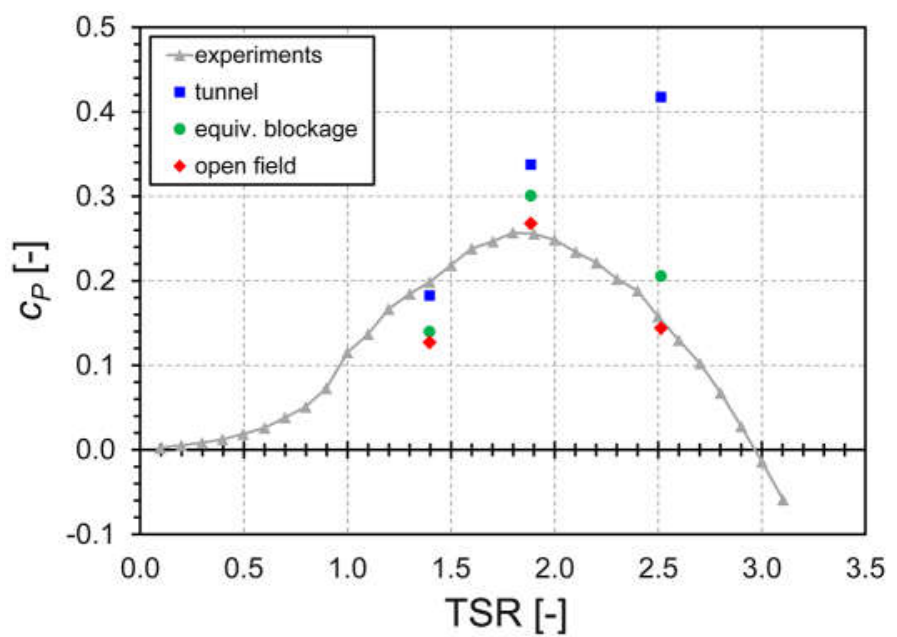

Fig. 8 - Comparison between experiments and simulations using different strategies in the selection of the later boundaries.

Upon examination of the figure, it is apparent that results using the "tunnel" configuration are notably far from the experimental trend, with a completely wrong prediction of the curve shape and of the modulus of maximum power coefficient. These 
results are indeed in agreement with the former reported in [40] made with the same domain dimensions with the OpenFOAM CFD package and the same turbulence model.

When the lateral boundaries are distanced, the agreement with experiments notably increases, reaching its maximum for the "open field" configuration, which is able to properly describe the shape of the curve and accurately predict the two stable power coefficient values. To further stress the differences induced by the boundaries on the computed flow field, Fig. 9 compares the $\mathrm{CFD}$ results at $\mathrm{TSR}=3.3$, where the difference is larger, in terms of velocity component in the streamwise direction normalized by that at the inlet, i.e. $U x / U x_{0}$.
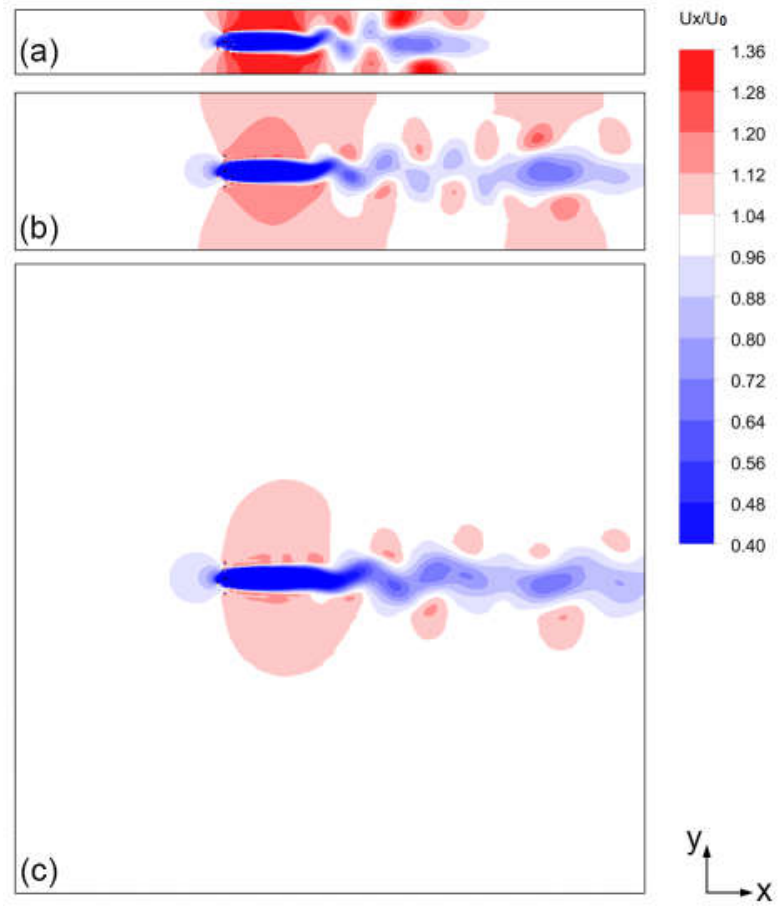

Fig. 9 - Normalized velocity component in the streamwise direction $\left(U x / U x_{0}\right)$ for three simulated domains at $\mathrm{TSR}=2.5$.

Upon examination of the figure, it is apparent that the lateral boundaries impose a strong acceleration to the flow when approaching the rotor. The turbine wake is also contracted and decades faster than in the "open field" configuration. Overall, the entire shape of the flow field around turbine is strongly modified: the turbine performance is consequently much different, as testified by Fig. 8. If the superior accuracy of $2 \mathrm{D}$ simulations using the "open field" configuration in predicting the performance curve was already discussed by Balduzzi et al. [27], the possibility of exploiting the unique wake measurements provided by the present experiments allowed to verify the reasons of this evidence. To do so, Fig. 10 compares the wake measurements at $\mathrm{TSR}=1.9$ (similar results were found for $\mathrm{TSR}=1.4$ but not reported here for brevity) with the numerical results extracted from the computed flow field in a virtual rake positioned exactly in the same position than the experimental one; CFD 


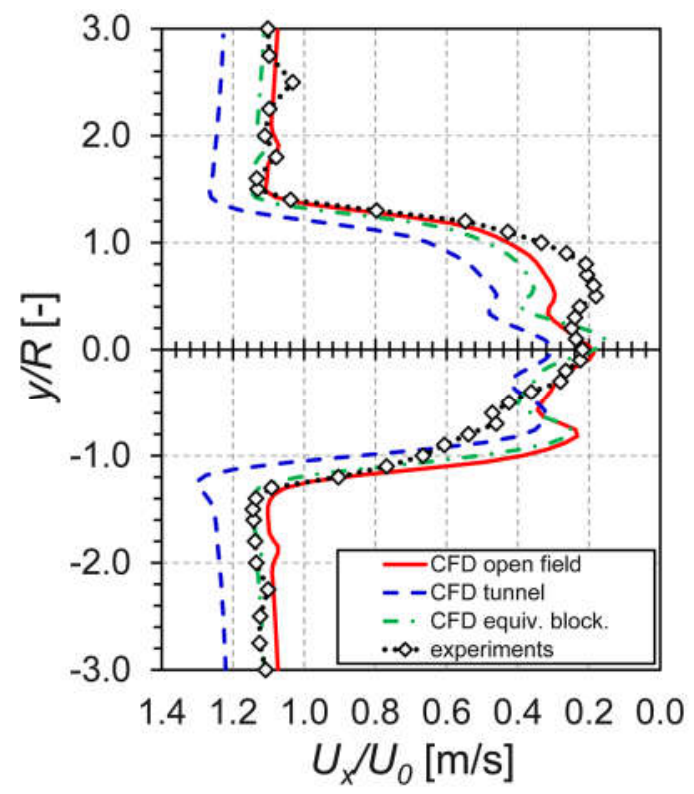

Fig. 10 - Normalized velocity profiles in the wake at TSR=1.9: comparison between experiments and simulations using different lateral boundaries.

Upon examination of the figure, it has to be noted that some differences are present between numerical simulations and experiments, especially regarding the non-symmetric nature of the wake. On the other hand, the comparison readily shows that the simulations using the lateral boundaries positioned at a distance equal to that of tunnel blades were also not able to properly predict the velocity levels both inside the wake and in its proximity, with a general overestimation in comparison to experiments. In fact, since in 2D simulations the flow cannot have velocity components along the blade span, the entire mass flow is indeed forced to pass through the rotor plane: by doing so, a "virtual" additional blockage is produced, as clearly demonstrated by the strong acceleration predicted by these simulations around the rotor (i.e. outside $-1<y / R<1$ ). In addition, the velocity deficit in the wake is also underestimated, leading to the excessive power production showed by Fig. 8 . Both the "equivalent blockage" and the "open field" simulations, conversely, properly predicted the velocity levels almost everywhere, with the "open field" approach being able to more closely match the peak of velocity deficit downstream the rotor and the overall shape of the wake. The accuracy of these latter CFD simulations was also testified by the comparison of normalized standard deviations for the wake measurements, reported in Fig. 11 for both TSRs available from the experimental campaign. 

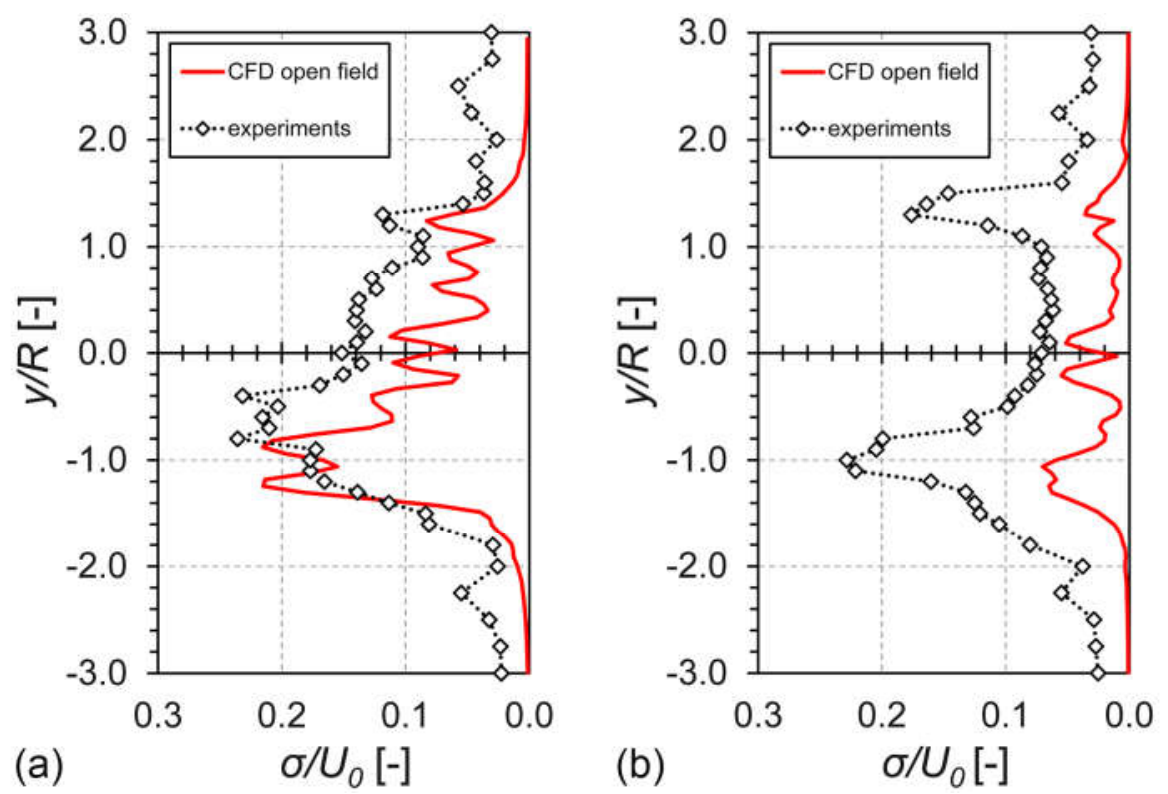

Fig. 11 - Normalized standard deviation of velocity measurements in the wake at $T S R=1.4$ (a) and $T S R=1.9$ (b): comparison between experiments and simulations using the "open field" configuration.

As expectable, CFD generally predicted lower values of the measurements' standard deviation with respect to experiments. Notwithstanding this, the distribution of standard deviation was sufficiently well reproduced, suggesting that the main aerodynamic phenomena inducing an increase of the measurements' scatter (e.g. vortices or separated flows) were captured. According to the results of Fig. 10, a discrepancy is noticed in the wake just behind the tower, where CFD generally tends to predicted more intense ripples with respect to experiments.

Based on the results of this first set of simulations, it was concluded that the "open field" configuration can be considered the most effective way of simulating Darrieus VAWTs whenever only two-dimensional simulations are available. In this view, this approach is assumed to provide valuable data for comparison even with experiments carried out in a tunnel (properly corrected for blockage, whenever needed).

\subsection{Detailed wake analysis}

The "open field" simulations at TSR=1.4 and TSR=1.9 were then further exploited to carry out detailed wake analyses, since for both functioning points experimental measurements were available from [39].

Figure 12 first compares the velocity profiles in the wake (a) and displays the normalized velocity field (b) in the streamwise direction predicted by CFD at TSR $=1.4$. 

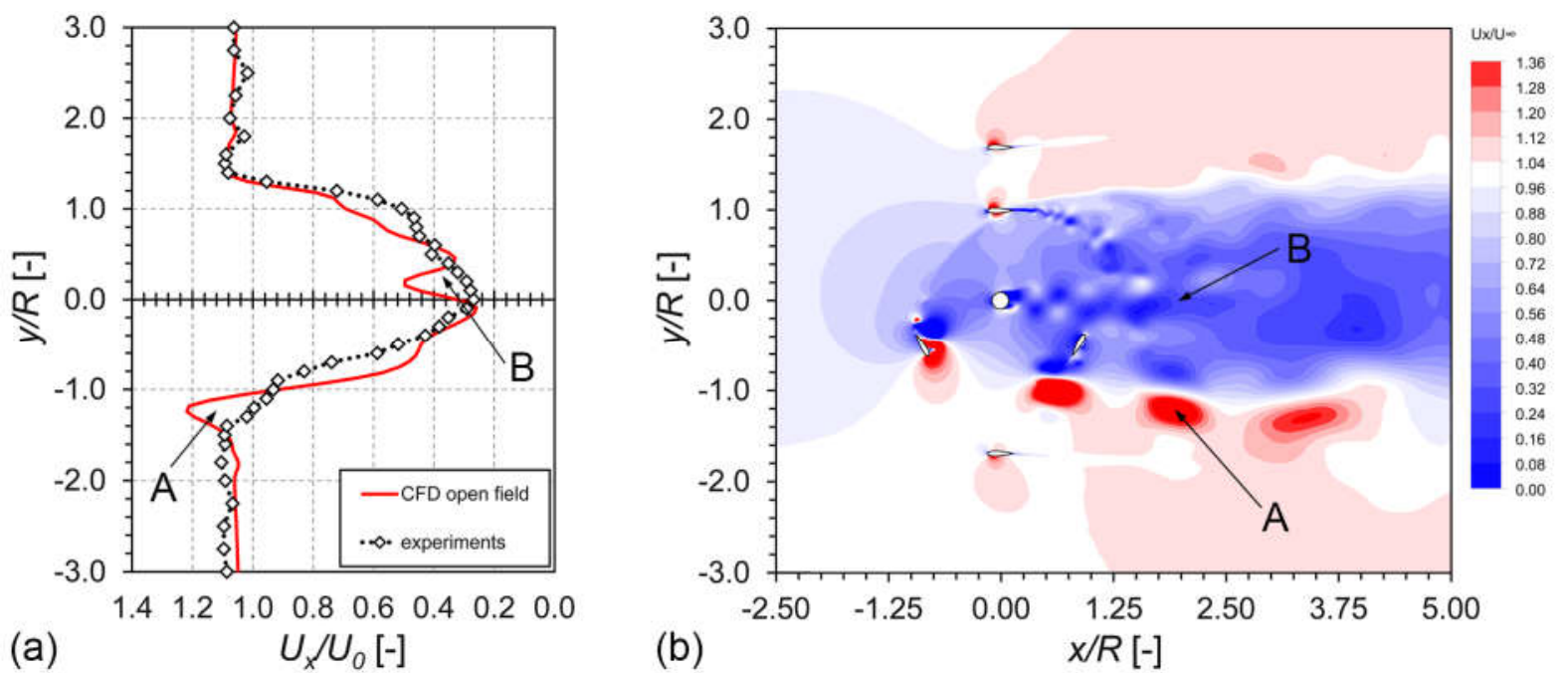

Fig. 12 - Normalized velocity in the wake at TSR=1.4: comparison between experiments and simulations (a) and computed velocity field (b).

Upon examination of Fig. 12(a), sound agreement can be noticed between experiments and simulations, even if these latter ones underestimated the wake deflection in the counterclockwise direction (i.e. the wake is more symmetric with respect to the center of the machine). Moreover, two main ripples are present in CFD simulations, marked as phenomenon " $A$ " and phenomenon " $B$ " in the figure. Even though it must be remembered that Fig. 12(a) indeed represents an averaged profile while Fig. 12(b) is a snapshot of the flow field at a given instant in time, it is readily arguable that the ripple A in CFD is connected to the strong vortices detached upwind from the blades and then convected by the flow downstream, whose intensity was probably overestimated by numerical simulations with respect to experiments. On the other hand, phenomenon $B$ is associated to an excessive velocity deficit in the wake of the tower, again not seen in experiments. Overall, it can be noticed that a superior uniformity was noticed in experiments with respect to simulations, probably due also the additional mixing in the third dimension which is not allowed by the 2D simulations.

Moving to TSR=1.9, Fig. 13 again compares the velocity profiles in the wake (a) and displays the normalized velocity field (b) in the streamwise direction predicted by CFD.
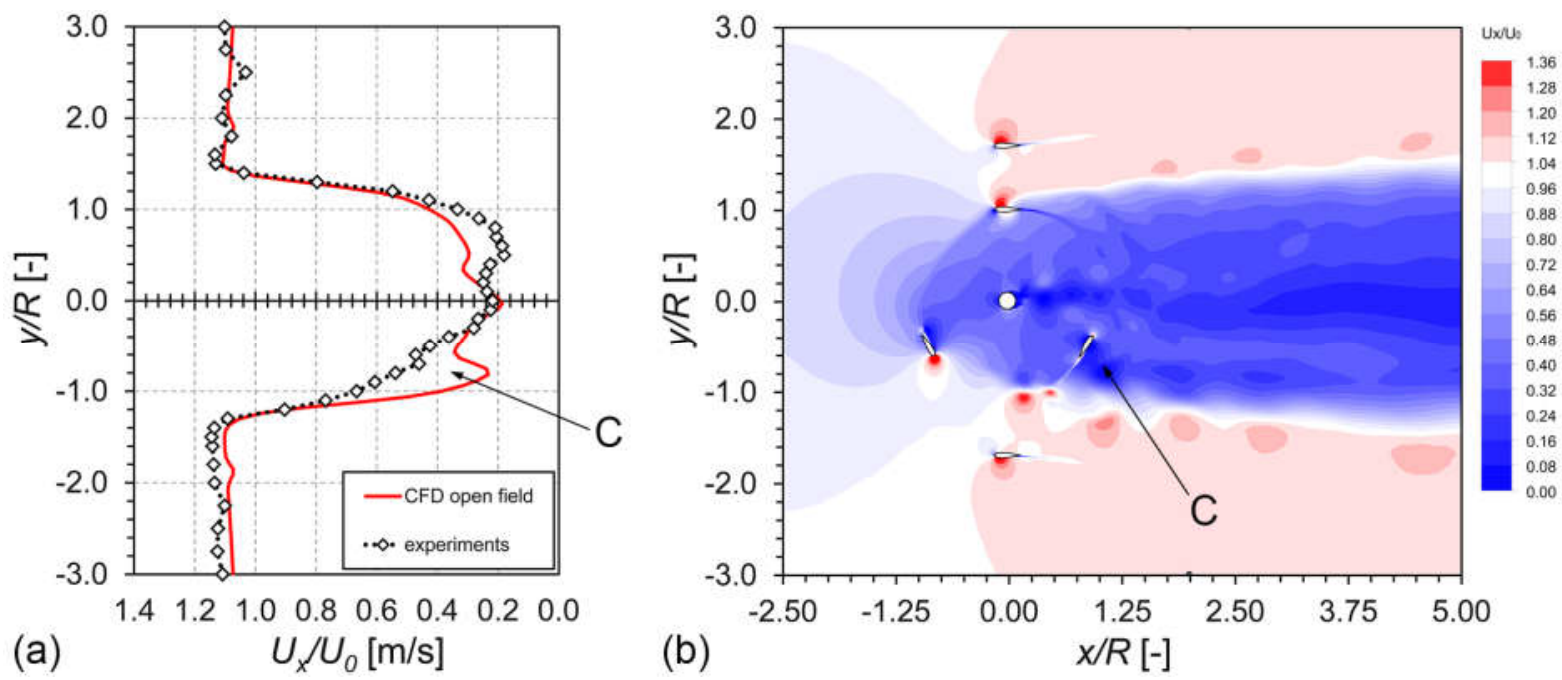

Fig. 13 - Normalized velocity in the wake at $T S R=1.9$ : comparison between experiments and simulations (a) and computed velocity field (b). 
The overall agreement is very good also at this TSR, with again only a slight underestimation of the wake deflection by CFD. A discrepancy (phenomenon "C") was also found at approximately $y / R=-0.8$, where simulations predict a wake with very low speed resulting from massive separations in the suction side of the blades entering the downwind region of the rotor. A small trace of such wake is visible also in experiments even though, as already noticed for $\mathrm{TSR}=1.4$, a smoother profile and a higher mixing was measured in experiments.

\subsection{Benefits of a transitional turbulence model at low tip-speed ratios}

As discussed in Section 3.4, whenever the attended blade Reynolds numbers are low enough to make one expect transitional effects (e.g. small rotors at low tip-speed ratios), the use of a transitional turbulence model has been suggested since it is thought to provide possible benefits in terms of simulations' accuracy [20-21]. On this basis, the functioning points in the unstable part of the performance curve of the rotor were simulated using both the $\kappa-\omega$ SST model and the $\gamma-R e_{\theta}$ model. An additional test at TSR=2.5 revealed that the change in the turbulence model did not induce any modification in the predicted torque profile at high TSRs. Figure 14 reports the comparison between the two sets of simulations.

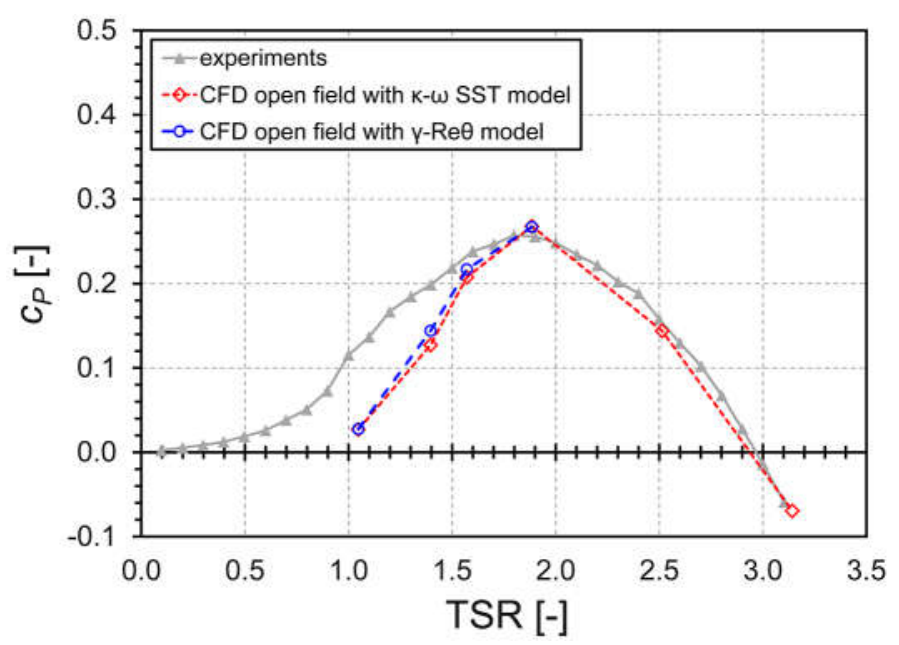

\section{Fig. 14 - Comparison between experiments and simulations using either the $\kappa-\omega$ SST model or the $\boldsymbol{\gamma}-\boldsymbol{R e}_{\theta}$ model at low TSRs.}

Upon examination of the figure, it is apparent that both models actually give coherent results, with the transitional model ensuring constantly a slightly higher performance (i.e. a little bit more similar to experiments) than the conventional SST model. However, none of the two models was able to take simulations substantially closer to experiments. This is probably due to the fact that in this region of the operating curve, the airfoils work in stalled conditions for a considerable fraction of the revolution, with severe flow separation phenomena and large-scale vortices detaching even from the leading edges of the airfoils (already discussed in the previous section). In these conditions, additional elements like the surface roughness, the trailing-edge refinement in the experimental model, etc. can play a fundamental role in setting the characteristics of such separations, which are however pivotal for the final torque production. More interesting information can be however obtained when again looking at the wake analysis. In particular, Fig. 15 reports the comparison between experiments and simulations at $\mathrm{TSR}=1.4$. 


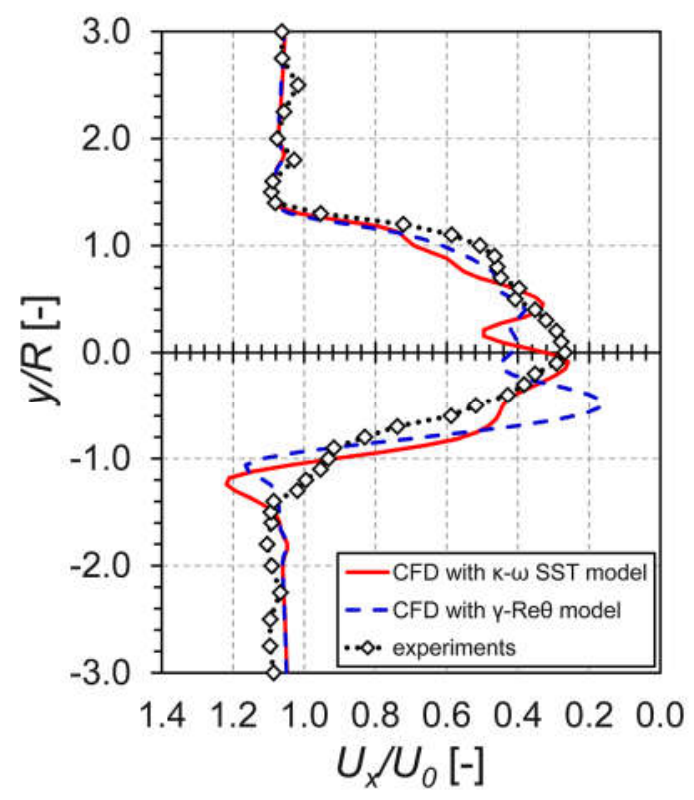

\section{Fig. 15 - Normalized velocity in the wake at TSR=1.4: comparison between experiments} and simulations using either the $\kappa-\omega$ SST model or the $\gamma$-Re $e_{\theta}$ model.

As one may notice, the use of the transitional turbulence model notably modified the description of the flow field around the turbine. The wake deflection is now a little more accurately described (see particularly the range between $0.8<y / R<1.4$ ) as well as the wake of the tower, were the fluctuations are now reduced. The same behaviour was noticed in all the four investigated TSRs. On the other hand an increased velocity deficit was noticed around $y / R=-0.5$, not present in experiments.

To further stress the impact of the different turbulence model, Fig. 16 reports the comparison of predicted vorticity contours at TSR $=1.4$ using either the $\kappa-\omega$ SST model (a) or the $\gamma$ - $\operatorname{Re}_{\theta}$ model (b).
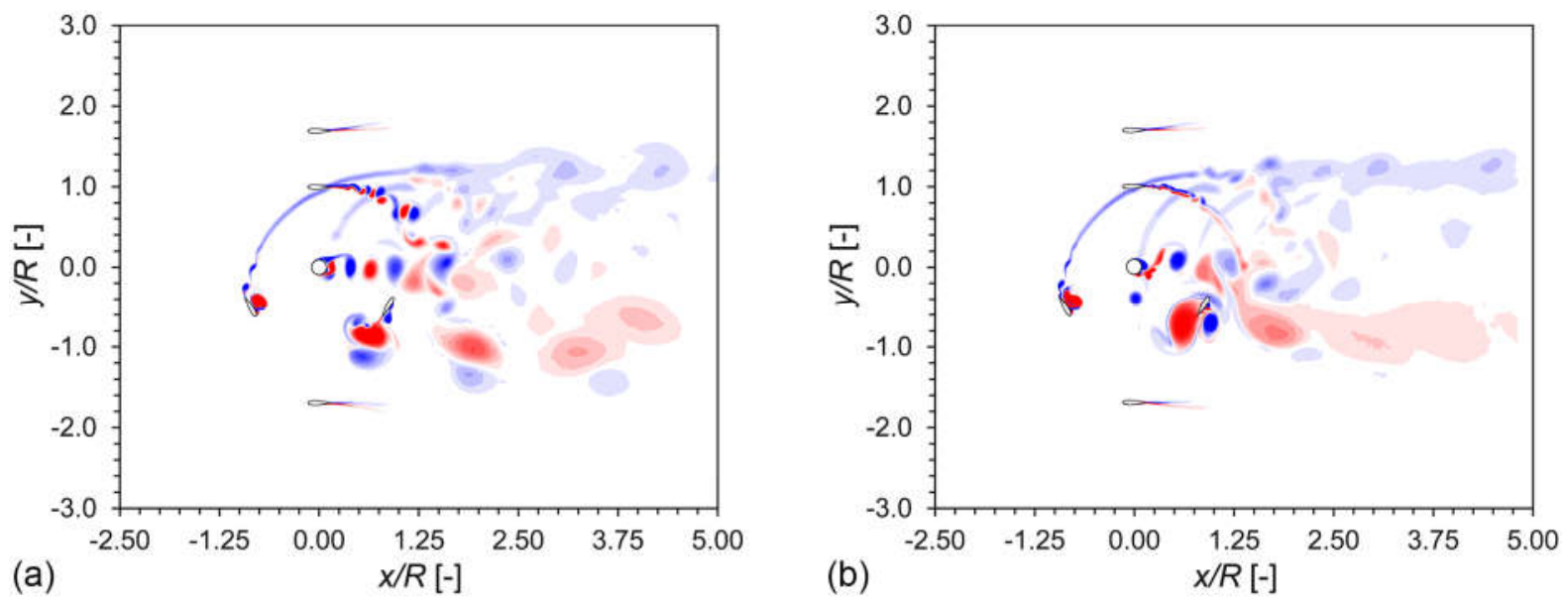

Fig. 16 - Vorticity contours at TSR=1.4 using either the $\kappa$ - $\omega$ SST model (a) or the $\gamma$-Re model (b).

Upon examination of the figure, it is apparent that remarkable differences are introduced in the flow field description by a different handling of turbulence closure. In particular, as expected based on the analysis of Fig. 15, the use of the transitional model leads to a different resolution of the propagation of stall vortices detaching from the blades at the end of the upwind sector. Moreover, the shedding taking place around the tower is also 
differently solved, avoiding the too strong ripples that were not seen in experiments. Overall, the transitional model apparently leads to a higher mixing of flow structures (vortices and wakes), more similar to what expected based on the experimental measurements. As a final remark, the $\gamma-R_{\theta}$ model was thought to provide a more accurate resolution of the flow past the blades and its use is then suggested whenever transitional effects may play a role in the airfoils' behavior.

\section{Conclusions}

In the study, unique experimental results collected in a water tow tank on the performance and wake characteristics of a H-Darrieus wind turbine were used to assess the effectiveness of a two-dimensional CFD U-RANS simulation approach.

Upon examination of cross-comparisons between experiments and simulations, it was apparent that, even though some simplifications are about to be introduced, a 2D simulation can provide quite accurate estimations of both the overall performance and the flow field description around the rotor with reasonable computational cost, on condition that proper settings are applied. In particular, it is here suggested that, in case of a two-dimensional simulation, the lateral boundaries of the computational domain must be placed sufficiently far from the rotor, in order to have an "open-field-like" configuration; by doing so, any artificial blockage due to the absence of the third dimension is avoided.

Moreover, the results further confirmed that, in case of medium-size rotor and low tipspeed ratios, the use of a transitional model for turbulence closure is suggested, since it ensures a more accurate description of the flow transition over the airfoils and of the vortices detachment for incidence angles higher than the stall one.

\section{Acknowledgements}

The authors would like to acknowledge Prof. Ennio Antonio Carnevale of the Università degli Studi di Firenze for supporting this research activity. Thanks are also due to Dr. Giacomo Benassai for his contribution to the simulations during his MSc thesis at the Università degli Studi di Firenze.

\section{References}

[1] Paraschivoiu I. Wind turbine design with emphasis on Darrieus concept. Polytechnic International Press: Montreal (Canada), 2002.

[2] Altan BD, Attlgan M, An experimental and numerical study on the improvement of the performance of Savonius wind rotor. Energy Conversion and Management 2008;49(12):3425-3432.

[3] Sarma NK, Biswas A, Misra RD. Experimental and computational evaluation of Savonius hydrokinetic turbine for low velocity condition with comparison to Savonius wind turbine at the same input power. Energy Conversion and Management 2014;83:88-98.

[4] Bhuyan S, Biswas A. Investigation on self-starting and performance characteristics of simple $\mathrm{h}$ and hybrid H-Savonius vertical axis wind rotors. Energy Conversion and Management 2014;87:859-867.

[5] Tjiu W, Marnoto T, Mat S, Ruslan MH, Sopian K. Darrieus vertical axis wind turbine for power generation I: Assessment of Darrieus VAWT configurations. Renewable Energy 2015; 75(March 2015): 50-67. DOI: 10.1016/j.renene.2014.09.038 
[6] Tjiu W, Marnoto T, Mat S, Ruslan MH, Sopian K. Darrieus vertical axis wind turbine for power generation II: Challenges in HAWT and the opportunity of multi-megawatt Darrieus VAWT development. Renewable Energy 2015; 75(March 2015):560-571. DOI: 10.1016/j.renene.2014.10.039

[7] Mohamed MH. Aero-acoustics noise evaluation of H-rotor Darrieus wind turbines. Energy 2014; 65(1): 596-604. DOI: 10.1016/j.energy.2013.11.031.

[8] Bianchini A, Ferrara G, Ferrari L, Magnani S. An improved model for the performance estimation of an H-Darrieus wind turbine in skewed flow. Wind Engineering 2012; 36(6): 667-686. DOI: 10.1260/0309-524X.36.6.667

[9] Balduzzi F, Bianchini A, Carnevale EA, Ferrari L, Magnani S. Feasibility analysis of a Darrieus vertical-axis wind turbine installation in the rooftop of a building. Applied Energy 2012; 97: 921-929. DOI: 10.1016/j.apenergy.2011.12.008

[10] Borg M, Collu M, Brennan FP. Offshore floating vertical axis wind turbines: advantages, disadvantages, and dynamics modelling state of the art. Marine \& Offshore Renewable Energy Congress, London (UK), 26-27 September, 2012.

[11] Mertens S. Wind Energy in the Built Environment. Multi-Science: Brentwood (UK), 2006.

[12] Aslam Bhutta MM, Hayat N, Farooq AU, Ali Z, Jamil ShR, Hussain Z, Vertical axis wind turbine - A review of various configurations and design techniques. Renewable and Sustainable Energy Reviews 2012;16(4):1926-1939.

[13] Bianchini A, Ferrara G, Ferrari L. Design guidelines for H-Darrieus wind turbines: Optimization of the annual energy yield. Energy Conversion and Management 2015;89:690-707. DOI: 10.1016/j.enconman.2014.10.038

[14] Brahimi M, Allet A, Paraschivoiu I. Aerodynamic analysis models for vertical-axis wind turbines. International Journal of Rotating Machinery 1995; 2(1): 15-21. DOI: $10.1155 /$ S1023621X95000169

[15] Bianchini A, Ferrari L, Carnevale EA. A model to account for the Virtual Camber Effect in the Performance Prediction of an H-Darrieus VAWT Using the Momentum Models. Wind Engineering 2011;35(4):465-482. DOI: 10.1260/0309-524X.35.4.465

[16] Marten D, Bianchini A, Pechlivanoglou G, Balduzzi F, Nayeri CN, Ferrara G, Paschereit CO, Ferrari L. Effects of airfoil's polar data in the stall region on the estimation of Darrieus wind turbines performance. Proc. of the ASME Turbo Expo 2016, Seoul, South Korea, June 13-17, 2016.

[17] Marten D, Lennie M, Pechlivanoglou G, Nayeri CD, Paschereit CO. Implementation, Optimization and Validation of a Nonlinear Lifting Line Free Vortex Wake Module within the Wind Turbine Simulation Code QBlade. Proc. of the ASME Turbo Expo 2015, Montréal, Canada, June 15-19, 2015.

[18] Deglaire P. Analytical Aerodynamic Simulation Tools for Vertical Axis Wind Turbines. Digital Comprehensive Summaries of Uppsala Dissertations from the Faculty of Science and Technology 2010, 704, ISSN 1651-6214.

[19] Amet E, Maitre T, Pellone C, Achard JL. 2D Numerical Simulations of Blade-Vortex Interaction in a Darrieus Turbine. Journal of Fluids Engineering 2009; 131: 111103.1111103.15. DOI: $10.1115 / 1.4000258$ 
[20] Rainbird J, Bianchini A, Balduzzi F, Peiro J, Graham JMR, Ferrara G, Ferrari L. On the Influence of Virtual Camber Effect on Airfoil Polars for Use in Simulations of Darrieus Wind Turbines. Energy Conversion and Management 2015;106:373-384. DOI: 10.1016/j.enconman.2015.09.053

[21] Bianchini A, Balduzzi F, Ferrara G, Ferrari L. Virtual incidence effect on rotating airfoils in Darrieus wind turbines. Energy Conversion and Management 2016; 111(1 March 2016): 329-338. DOI: 10.1016/j.enconman.2015.12.056

[22] Simao-Ferreira C, van Zuijlen A, Bijl H, van Bussel G, van Kuik G. Simulating dynamic stall on a two-dimensional vertical-axis wind turbine: verification and validation with particle image velocimetry data. Wind Energy 2010; 13: 1-17. DOI: $10.1002 /$ we. 330

[23] Salvadore F, Bernardini M, Botti M. GPU accelerated flow solver for direct numerical simulation of turbulent flows. Journal of Computational Physics 2013; 235: 129-142. DOI: $10.1016 /$ j.jcp.2012.10.012

[24] Balduzzi F, Bianchini A, Gigante FA, Ferrara G, Campobasso MS, Ferrari L. Parametric and Comparative Assessment of Navier-Stokes CFD Methodologies for Darrieus Wind Turbine Performance Analysis. Proc. of the ASME Turbo Expo 2015, Montreal, Canada, June 15-19, 2015. DOI: 10.1115/GT2015-42663

[25] Howell R, Qin N, Edwards J, Durrani N. Wind tunnel and numerical study of a small vertical axis wind turbine. Renewable Energy 2010; 35: 412-422. DOI: 10.1016/j.renene.2009.07.025

[26] Raciti Castelli M, Englaro A, Benini E. The Darrieus wind turbine: Proposal for a new performance prediction model based on CFD. Energy 2011; 36: 4919-4934. DOI: 10.1016/j.energy.2011.05.036

[27] Balduzzi F, Bianchini A, Maleci R, Ferrara G, Ferrari L. Critical issues in the CFD simulation of Darrieus wind turbines. Renewable Energy 2016; 85(01): 419-435. DOI: 10.1016/j.renene.2015.06.048

[28] Almohammadi KM, Ingham DB, Ma L, Pourkashan M. Computational fluid dynamics (CFD) mesh independency techniques for a straight blade vertical axis wind turbine. Energy 2013; 58(1 September 2013): 483-493. DOI: 10.1016/j.energy.2013.06.012

[29] Balduzzi F, Bianchini A, Ferrara G, Ferrari L. Dimensionless numbers for the assessment of mesh and timestep requirements in CFD simulations of Darrieus wind turbines. Energy 2016; 97(15 February 2016): 246-261. DOI: 10.1016/j.energy.2015.12.111

[30] Daróczy L, Janiga G, Petrasch K, Webner M, Thévenin D. Comparative analysis of turbulence models for the aerodynamic simulation of H-Darrieus rotors. Energy 2015; 90(1 October 2015): 680-690. DOI: 10.1016/j.energy.2015.07.102

[31] Lam HF, Peng HY. Study of wake characteristics of a vertical axis wind turbine by two- and three-dimensional computational fluid dynamics simulations. Renewable Energy 2016; 90(May 2016): 386-398. DOI: 10.1016/j.renene.2016.01.011

[32] Ghosh A, Biswas A, Sharma KK, Gupta R. Computational analysis of flow physics of a combined three bladed Darrieus Savonius wind rotor. Journal of the Energy Institute 2015; 88(4): 425-437. DOI: 10.1016/j.joei.2014.11.001 
[33] Alaimo A, Esposito A, Messineo A, Orlando C, Tumino D. 3D CFD Analysis of a Vertical Axis Wind Turbine. Energies 2015; 8: 3013-3033. DOI: 10.3390/en8043013

[34] De Marco A, Coiro DP, Cucco D, Nicolosi F. A Numerical Study on a Vertical-Axis Wind Turbine with Inclined Arms. International Journal of Aerospace Engineering 2014; 2014: 1-14. DOI: 10.1155/2014/180498

[35] Orlandi A, Collu M, Zanforlin S, Shires A. 3D URANS analysis of a vertical axis wind turbine in skewed flows. Journal of Wind Engineering and Industrial Aerodynamics 2015; 147(December 2015): 77-84. DOI: 10.1016/j.jweia.2015.09.010

[36] Bachant P, Wosnik M. Modeling the near-wake of a vertical-axis cross-flow turbine with 2-D and 3-D RANS. Journal of Renewable and Sustainable Energy 2016;8(5):053311-1-10. DOI: 10.1063/1.4966161

[37] Balduzzi F, Drofelnik J, Ferrara G, Ferrari L, Campobasso MS. Darrieus Wind Turbine Blade Unsteady Aerodynamics: a Three-Dimensional Navier-Stokes CFD assessment. Paper submitted to: Energy.

[38] Barone M, Griffith T, Berg J. Reference model 2: rev 0 rotor design. Tech. Rep. SAND2011-9306, Sandia National Laboratories, November 2011.

[39] Bachant, P, Wosnik, M. Characterising the near-wake of a cross-flow turbine. Journal of Turbulence 2015; 16(4):392-410. DOI:10.1080/14685248.2014.1001852

[40] Bachant, P, Wosnik, M. Effects of Reynolds number on the energy conversion and near-wake dynamics of a high solidity vertical-axis cross-flow turbine. Energies 2016;9(2):73/1-18. DOI:10.3390/en9020073

[41] Bachant, P, Wosnik, M. UNH-RVAT baseline performance and near-wake measurements: Reduced dataset and processing code. Online tech. rep. DOI: 10.6084/m9.figshare. 1080781

[42] Ansys, Inc., 2015, Fluent Theory Guide, release 16.1.

[43] Maître T, Amet E, Pellone C, Modeling of the Flow in a Darrieus Water Turbine: Wall Grid Refinement Analysis and Comparison with Experiments. Renewable Energy 2013;51:497-512. DOI: 10.1016/j.renene.2012.09.030

[44] Balduzzi F, Bianchini A, Maleci R, Ferrara G, Ferrari L. Blade design criteria to compensate the flow curvature effects in H-Darrieus wind turbines. Journal of Turbomachinery 2015;137(1):1-10. DOI: 10.1115/1.4028245

[45] Menter FR, Two-Equation Eddy-Viscosity Turbulence Models for Engineering Applications. AIAA J. 1994:32(8):1598-1605.

[46] Gigante FA, Balduzzi F, Bianchini A, Yan M, Ferrara G, Campobasso MS, Ferrari L. On the Application of the Reynolds-Averaged Navier-Stokes Equations and the Shear Stress Transport Turbulence Model for the Performance Estimation of Darrieus Wind Turbines. Paper submitted to: Journal of Wind Engineering and Industrial Aerodynamics.

[47] Langtry RB, Menter FR, Correlation-based transition modeling for unstructured parallelized computational fluid dynamics codes. AIAA Journal 2009:47(12):28942906.

[48] Lanzafame R, Mauro S, Messina M, 2D CFD modeling of H-Darrieus wind turbines using a transition turbulence model. Energy Procedia 2014;45:131-140. 
[49] Bianchini A, Ferrari L, Magnani S, Start-up behavior of a three-bladed H-Darrieus VAWT: experimental and numerical analysis. Proc. of the ASME Turbo Expo 2011, Vancouver (Canada), June 6-10; 2011. DOI: 10.1115/GT2011-45882

[50] Hoerner SF. Fluid-Dynamic Drag. Hoerner Fluid-Dynamics, 1965.

[51] Bianchini A, Ferrari L, Magnani S. On the effects of a skewed flow on the performance of a three-bladed H-Darrieus turbine: experimental and theoretical analyses. Proceedings of the International Conference on Applied Energy (ICAE) 2012, Suzhou (China), July 5-8, 2012. 